\title{
Perceived Racial Discrimination and the Health of Black Youth in Ohio
}

\author{
Kenneth J. Steinman ${ }^{1}$; Townsand Price-Spratlen²; Christopher Browning ${ }^{2}$ \\ ${ }^{1}$ College of Education and Human Ecology, The Ohio State University, Columbus, OH \\ ${ }^{2}$ Department of Sociology, The Ohio State University, Columbus, $\mathrm{OH}$ \\ Corresponding Author: Kenneth J. Steinman, 1787 Neil Avenue, Columbus, OH 43210, (614) 599-4763, steinman.13@osu.edu \\ Submitted August 20, 2020 Accepted November 15, 2020
}

\section{ABSTRACT}

Background: Perceived racial discrimination (PRD) is known to harm youth, yet few studies use large, representative samples or study caregivers' perceptions of their children's experiences with unjust treatment. We examined how such a measure of PRD was associated with demographic characteristics as well as with physical and mental health outcomes for Black youth across Ohio.

Methods: The 2019 Ohio Medicaid Assessment Survey was a complex telephone survey with a representative sample of 31558 adults, 907 of whom completed a proxy interview for a youth in the household who was Black and age 6 to 18 years. One item from an Adverse Childhood Experiences (ACEs) scale assessed PRD: "To the best of your knowledge, has [name] ever experienced any of the following? Treated or judged unfairly because of [her/his] race or ethnic group."

Results: Weighted analyses found that PRD was more common among Black youth who were older, from higher income families, and lived in rural counties. Perceived racial discrimination was also associated with frequent mental distress and with having an emotional or behavioral problem that needs treatment or counseling. It was not associated with any physical health outcomes measured.

Conclusion: Our findings resemble those from other studies that use more extensive measures of PRD. While no substitute for extensive measures, the ACEs single-item measure may expand opportunities to study PRD in subgroup analyses of larger, representative samples. Yet our findings and those from other studies already provide considerable evidence that efforts to improve Black youth's mental health should consider their experience with PRD.

Keywords: Racial discrimination; Health outcomes; Child; Adolescent; African American

\section{INTRODUCTION}

Recent events highlight the United States' legacy of racism and its enduring effects on the health and well-being of young people. Much of the discourse has focused on structural racism-the selfperpetuating institutions (eg, education, criminal justice, financial) that privilege white Americans over others. Yet individual experiences with racial discrimination can also have a profound negative effect on health and well-being. ${ }^{1}$

One limitation of research in this area is that studies have largely relied on convenience samples. ${ }^{2,3}$ While valuable, these studies may not be generalizable across settings and may bias estimates of the association between youth's perceptions of racial discrimination and their health outcomes. ${ }^{3}$ In order to expand our understanding of racial discrimination, there is a great need for studies that can produce generalizable findings and systematically examine racial discrimination in subgroups (eg, urban versus rural youth).

Yet such studies are expensive, and few have been designed to examine racial discrimination. Instead, researchers must rely on studies designed for another purpose (eg, adolescent health) that may have limited measures of racial discrimination. It is unclear whether such limited measures are robust enough to detect an association with health outcomes. This paper uses a large, repre-

(c) 2020 Kenneth J. Steinman; Townsand Price-Spratlen; Christopher Browning. Originally published in the Ohio Journal of Public Health (http://ojph.org) December 2020. This article is published under a Creative Commons Attribution 4.0 International License (http://creativecommons.org/licenses/by/4.0/) 
sentative dataset from Ohio to examine whether a brief, proxy measure of racial discrimination is associated with physical and mental health outcomes. To the extent that the measure yields findings that parallel those from other studies, we may have greater confidence that large, representative studies with brief measures can provide a useful contribution to the research literature in this area.

Racial discrimination involves "individuals and larger institutions, deliberately or without intent, treat[ing] racial groups differently, resulting in inequitable access to opportunities and resources." 1 Studies, like ours, that employ subjective measures only capture those instances of which the respondent is aware. For this reason, the term "perceived racial discrimination" (PRD) is preferred. ${ }^{4}$

Another limitation of previous research on PRD relates to exactly who is perceiving racial discrimination. Most studies ask youth or adults to report their own experiences, and some ask youth to report on their caregivers' experiences. Few, however, ask adult caregivers to report on their child's experiences with unjust treatment. The most recent systematic review found no such examples, ${ }^{2}$ although 2 recent national studies use such a measure.5,6 This gap is significant, as proxy reports may be influenced by the respondent's own experiences and thus reflect parenting strategies as well as the intergenerational, indirect transmission of the trauma of racism.7,8 Also, some caregivers may recognize unfair treatment that the child is too young to understand.

Considerable research has documented the association of PRD with youth's physical and mental health outcomes such as anxiety, depression, and preterm births. ${ }^{2}$ The most recent meta-analysis and review found that PRD may have stronger effects for mental health than physical health outcomes, ${ }^{2,3}$ although an earlier review found no such differences. ${ }^{9}$

Many racial and ethnic minority groups experience discrimination, each of which merits distinct attention. Scholars often focus on Black youth in particular because of the frequency with which they experience discrimination as well as its intergenerational transfer, and long-term adverse effects.7,8 Americans of African descent bear a unique historic legacy in the United States and, as the largest racial minority group in Ohio, are the focus of the present study.

\section{METHODS}

\section{Participants and Procedures}

Because this study is based on publicly available, deidentified data, this study was exempt from review by the Institutional Review Board of The Ohio State University.

The 2019 Ohio Medicaid Assessment Survey (OMAS) assessed health status and health system-related information from the selfreports of noninstitutionalized adults who reside in Ohio. The 2019 OMAS was structured as a stratified random digit dial (RDD) dual-frame (cell phone and landline phone) complex designed (multiple strata) telephone survey. Survey weighting was performed in stages at the county, regional, state, oversample, and cell phone level. It was fielded with the assistance of the Research Triangle Institute (RTI), International. Multimode data were collected, including phone sample data through random digit dialing and web-based or paper mail versions through address-based sampling. Overall, 31558 surveys of Ohioans 19 years of age and older and proxy interviews for 7404 youth 18 years of age and younger were completed: 30068 by phone, 950 by web, and 540 by mail-in paper survey. Data for the present study focused on the subpopulation of 907 proxy interviews involving Black youth ages 6 to 18 years. The study protocol asked adult respondents who reported that a youth lived in the home to continue the survey with "... the adult in this household who best knows about [child's name]'s health insurance coverage and health status." Whereas "caregiver" is a reasonable term to describe these adult respondents, this is admittedly an assumption. The 2019 OMAS was the eighth iteration of the survey, and additional details regarding methods are available at https://grc.osu.edu/OMAS.

\section{Measures}

\section{Demographics}

Missing values for demographic variables were imputed using a weighted sequential hotdeck imputation procedure. When a respondent reported the child's race as "Black" or "African American" and no other category, they were classified as Black for this study. Of the 907 proxy interviews of Black youth ages 6 to 18 years, 24 were missing data on youth race $(2.6 \%)$ but were imputed as Black. Standard survey items assessed age, sex, and income as percentage of the federal poverty level. County type distinguished among rural counties (eg, Vinton) as well as larger (eg, Franklin) and smaller (eg, Richland) metropolitan counties and suburban counties (eg, Licking) using criteria that OMAS study directors developed in 2004 in consultation with the National Research Council's Committee on Population and Demography (Tim Sahr, phone communication July 2020). For the subpopulation in this study, $4.6 \%$ of the county type values were imputed.

\section{Racial discrimination}

Perceived racial discrimination was measured by a single item from a series of 8 items on Adverse Childhood Experiences that have been used in other studies:5,6 "To the best of your knowledge, has [youth's name] ever experienced any of the following?" One of these items was "Treated or judged unfairly because of his/her race or ethnic group." When a caregiver responded "yes," the youth was classified as having PRD. Thirty-six cases (4.0\%) were missing data on this variable.

\section{Health outcomes}

Health outcomes included the respondent's perception of the youth's overall health status, "In general, how would you describe [youth's name]'s health? Would you say [her/his] health is excel- 
lent, very good, good, fair, or poor?” Responses were collapsed into "fair" or "poor" versus "excellent," "very good," or "good." Obesity was based on the youth's caregiver-reported body mass index (BMI) being at or above the 95th percentile for youth of the same age and sex. Asthma was assessed by "Has a doctor or other health professional ever told you that [youth's name] has asthma?" and developmental disability by a similar item, "Does [youth's name] have a developmental disability?" A single item measured frequent mental distress, "Now, thinking about your child's mental health, which includes stress, depression, and problems with emotions or substance use, for how many days, during the past 30 days did a mental health condition or emotional problem keep [youth's name] from participating in school, social relationships with friends, or other usual activities?" (For youth younger than 13, the phrase "or substance use" was omitted.) Responses of 7 days or greater were classified as frequent mental distress. This classification does not represent a clinical diagnosis, but it does represent a caregiver's perception of a meaningful degree of impairment in the youth's life during the previous month. Three items adapted from a screener for youth with special health care needs ${ }^{10}$ used the stem "Because of a physical, mental, emotional condition lasting 6 months or more, does [youth's name] ..." The specific items includ- ed, “...currently need or use medicine prescribed by a doctor or other health care professional, other than vitamins?"; “...need or get special therapy such as physical, occupational, or speech therapy?"; and "have any kind of emotional, developmental, or behavioral problem for which [she/he] needs or gets treatment or counseling?"

\section{Statistical Analyses}

Analyses were performed using Stata version 16 and estimates were weighted to be representative of all noninstitutionalized Black youth, ages 6 to 18 years in Ohio. Most of the health outcomes were not asked of children younger than 6 , as doing so would be inappropriate. (For instance, asthma screening procedures are not accurate before 5 years of age, so few young children receive such a diagnosis.) Moreover, PRD was much less common for youth ages 0 to 5 years $(3.3 \%, 95 \%$ CI 1.6\%-5.0\%).

\section{RESULTS}

The prevalence of PRD (Table 1) was similar for females and males but was more common among 13 - to 18 -year-olds $(22.0 \%, 95 \% \mathrm{CI}$ $17.3 \%-26.7 \%$ ) compared to 6 - to 12 -year-olds $(13.6 \%$, $95 \% \mathrm{CI}$ $9.8 \%-17.5 \%$ ). About $40.3 \%$ (95\%CI 29.4\%-51.2\%) of Black youth

\section{Table 1. Percent of Black Youth Perceived to Have Experienced Racial Discrimination}

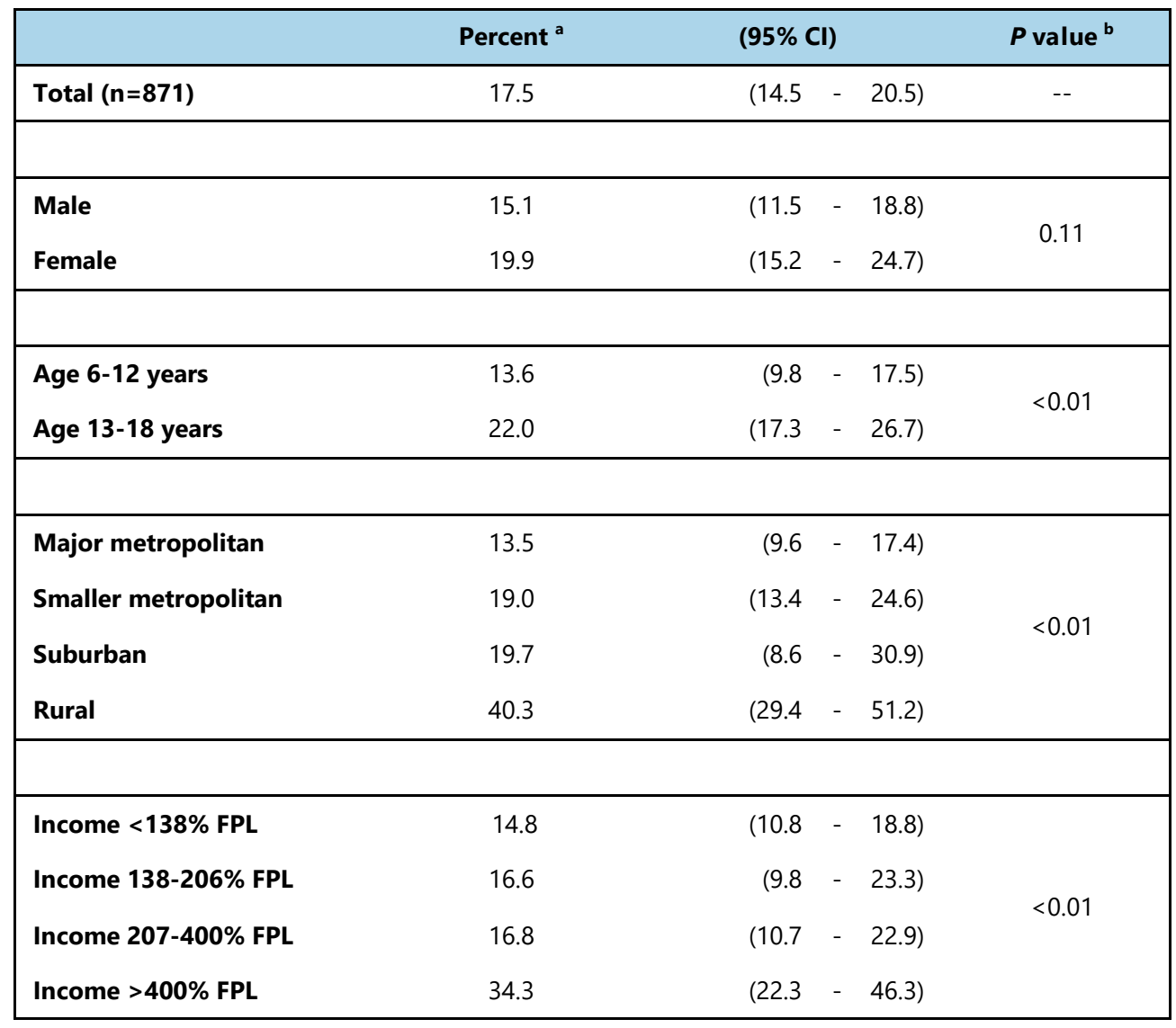

Abbreviations: $\mathrm{Cl}$, confidence interval; FPL, Federal Poverty Level

astimates are weighted to be representative of all noninstitutionalized Black youth, ages 6-18 years in Ohio.

${ }^{\mathrm{b}} P$ value of Pearson $\chi^{2}$ test 
living in rural counties experienced PRD—nearly 3 times the estimate for Ohio's 3 largest metropolitan counties (Cuyahoga, Franklin, Hamilton; $13.5 \%$ 95\%CI 9.6\%-17.4\%) and more than twice as likely as those living in other counties. And youth with family incomes greater than $400 \%$ FPL were more than twice as likely as youth from lower incomes to have PRD.

Analyses found that PRD was not associated with youth's obesity, asthma, developmental disability, needing/using prescribed medication, or needing/using special therapy; nor was it associated with overall fair/poor health status (Table 2). It was, however, associated with youth's frequent mental distress and with having an emotional, developmental, or behavioral problem for which [she/he] needs or gets treatment or counseling. For example, among Black youth in Ohio ages 6 to 18 years, $10.7 \%$ of those with PRD experienced frequent mental distress, compared to only $2.6 \%$ who did not report PRD—a 4-fold difference.

\section{DISCUSSION}

Our finding that PRD is associated with mental, but not physical health outcomes among Black youth resembles findings from many other studies, even as the research literature is not always consistent. ${ }^{2,3}$ This suggests that other researchers could use this brief measure of PRD to help expand research on the topic.

The greater prevalence of PRD in rural counties might be attributed to these areas being predominantly White. Other studies have found that living in a predominantly White community was associated with an increase in youth experiencing PRD.11,12 In predominantly White settings, young Black people may be more likely to be treated differently because they appear "different" on a sociallymeaningful category-race. ${ }^{11}$

Similarly, our finding of a positive association between PRD and income parallels previous research that finds greater PRD among Blacks with higher socioeconomic status.12 Wealthier children (and their caregivers) may have more access to education, and therefore may be more likely to perceive racial discrimination. Curiously, this study's findings on income conflict with two recent studies that employed the same measure of PRD yet found no bivariate association.5,6 The inconsistent results might be explained by age of their data-from 2011-2012. National attitudes about race have shifted markedly since then. ${ }^{13}$ In addition, the difference may reflect something about Ohio, as some research suggests Ohio departs from national averages on measures of racial attitudes. ${ }^{13,14}$

\section{Table 2. Physical and Mental Health Outcomes Among Black Youth who Have Versus Have Not Perceived Racial Discrimination}

\begin{tabular}{|c|c|c|c|c|c|}
\hline & \multicolumn{2}{|c|}{$\begin{array}{l}\text { Among youth who have } \\
\text { perceived racial } \\
\text { discrimination }\end{array}$} & \multicolumn{2}{|c|}{$\begin{array}{l}\text { Among youth who have } \\
\text { not perceived racial } \\
\text { discrimination }\end{array}$} & \multirow[b]{2}{*}{$P$ value ${ }^{b}$} \\
\hline & Percent ${ }^{a}$ & $(95 \% \mathrm{Cl})$ & Percent $^{a}$ & $95 \% \mathrm{Cl}$ & \\
\hline Fair/poor health status & 11.1 & $(5.6-16.6)$ & 6.6 & $(3.9-9.2)$ & 0.11 \\
\hline Obesity & 27.0 & $(18.5-35.5)$ & 32.4 & $(27.7-37.1)$ & 0.29 \\
\hline Asthma & 29.0 & $(20.4-37.7)$ & 23.4 & $(19.4-27.3)$ & 0.23 \\
\hline Developmental disability & 16.5 & $(10.2-22.9)$ & 14.2 & $(10.8-17.7)$ & 0.52 \\
\hline $\begin{array}{l}\text { Needs or uses prescribed } \\
\text { medication }\end{array}$ & 26.8 & $(19.2-34.5)$ & 20.4 & $(16.7-24.1)$ & 0.11 \\
\hline $\begin{array}{l}\text { Needs or gets special therapy } \\
\text { (eg, physical therapy) }\end{array}$ & 9.6 & $(4.5-14.6)$ & 9.1 & $(6.3-11.9)$ & 0.85 \\
\hline $\begin{array}{l}\text { Needs or gets counseling or } \\
\text { treatment for any kind of emotional, } \\
\text { developmental, or behavioral problem }\end{array}$ & 25.1 & $(17.4-32.8)$ & 15.1 & $(11.7-18.5)$ & $<0.01$ \\
\hline Frequent mental distress & 10.7 & $(5.5-16.0)$ & 2.6 & $(1.3-3.9)$ & $<0.01$ \\
\hline
\end{tabular}

a Estimates are weighted to be representative of all noninstitutionalized Black youth, ages 6-18 years in Ohio.

${ }^{b} P$ value of Pearson $x^{2}$ test 


\section{Limitations}

Perceived racial discrimination cannot be rigorously measured by a single item, especially when it involves a caregiver reporting on behalf of a child. The estimate that $17.5 \%$ of Black youth in Ohio experience PRD, for instance, is almost certainly low, as studies with more complete measures yield higher prevalence rates. ${ }^{15,16}$ While the brief measure may have some utility, it should not be used to assess the prevalence of PRD.

This study's cross-sectional design meant that we could not determine the causal influence of PRD on health, only whether they are associated. Thus, these findings may reflect the harmful effects of prejudice as well as evidence that Black youth with mental health issues may be more likely to experience or perceive racial discrimination. ${ }^{5}$

\section{PUBLIC HEALTH IMPLICATIONS}

Efforts to improve the mental health of Black youth should consider their experience with racism, especially for those living in rural areas or higher income households. Health care providers can best serve their patients by ensuring that "all patients and families know that they are welcome, that they will be treated with mutual respect, and that high-quality care will be delivered regardless of background."17(p5) Given the pervasive racial/ethnic disparities in youth's access to mental health care, ${ }^{18}$ Black families deserve clinical encounters that promote, rather than undermine, their youth's well-being. And public health efforts should ensure that rural and higher income youth are not neglected in preventing racial discrimination and associated mental health issues.

\section{ACKNOWLEDGMENTS}

The authors acknowledge and thank Tim Sahr and the staff of the Ohio Colleges of Medicine Government Resource Center for leadership in administering OMAS.

\section{REFERENCES}

1. Williams DR, Lawrence JA, Davis BA. Racism and health: evidence and needed research. Annu Rev Public Health. 2019;40:105-125. https://doi.org/10.1146/annurev-publhealth-040218-043750

2. Priest N, Paradies Y, Trenerry B, Truong M, Karlsen S, Kelly Y. 2013. A systematic review of studies examining the relationship between reported racism and health and wellbeing for children and young people. Soc Sci Med. 2013;95:115-27.

https://doi.org/10.1016/j.socscimed.2012.11.031

3. Paradies Y, Ben J, Denson N, Elias A, Priest N, et al. Racism as a determinant of health: a systematic review and meta-analysis. PLoS One. $2015 ; 10$. https://doi.org/10.1371/journal.pone.0138511

4. Seaton EK, Iida M. Racial discrimination and racial identity: daily moderation among black youth. Am Psychologist. 2019;74 (1):117-127. https://doi.org/10.1037/amp0000367

5. Montes G. US children with special health care needs and ethnic discrimination: results from multivariate modeling. World J Pediatr. 2019;Apr;15(2):182-189. https://doi.org/10.1007/s12519-018-0219-6
6. Anderson AT, Luartz L, Heard-Garris N, Widaman K, Chung PJ. The detrimental influence of racial discrimination on child health in the United States, J Natl Med Assoc. 2020;112:411-422.

https://doi.org/10.1016/j.jnma.2020.04.012

7. Colen, CG, Li Q., Reczek, C, Williams, DR. The intergenerational transmission of discrimination: children's experiences of unfair treatment and their mothers' health at midlife. J Health Soc Beh. 2019;60(4):474492. https://doi.org/10.1177/0022146519887347

8. Heard-Garris, NJ, Cale, M, Camaj, L, Hamati, MC, Dominguez, TP. Transmitting Trauma: a systematic review of vicarious racism and child health. Soc Sci Med. 2018;199:230e240. https://doi.org/10.1016/j.socscimed.2017.04.018

9. Pascoe EA, Smart Richman L. Perceived discrimination and health: a meta-analytic review. Psychol Bull. 2009;135:531-54. https://doi.org/10.1037/a0016059

10. Bethell CD, Read D, Stein RE, Blumberg SJ, Wells N, Newacheck PW. Identifying children with special health care needs: development and evaluation of a short screening instrument. Ambul Pediatr. 2002;2 (1):38-48. https://doi.org/10.1367/1539-4409(2002)002\%3C0038:ICWSHC\%3E2.0.CO;2

11. Assari, S, Gibbons FX, Simons, RL. Perceived discrimination among black youth: an 18-year longitudinal study. Behav Sci. 2018;44(8):111. https://doi.org/10.3390/bs8050044

12. Assari S. Does school racial composition explain why high income black youth perceive more discrimination? A gender analysis. Brain Sci. 2018 Jul 30;8(8):140. https://doi.org/10.3390/brainsci8080140

13. Smith CW, Kreitzler RJ, Suo F. The dynamics of racial resentment across the 50 US states. Perspectives on Politics. 2020;18(2):527-538. https://doi.org/10.1017/S1537592719002688

14. Chae DH, Clouston S, Hatzenbuehler ML, et al. Association between an internet- based measure of area racism and black mortality. PLoS One. 2015;10(4):e0122963. https://doi.org/10.1371/journal.pone.0122963

15. Seaton EK, Iida M. Racial discrimination and racial identity: daily moderation among black youth. Am Psychologist. 2019;74(1):117-127. https://doi.org/10.1037/amp0000367

16. Seaton EK, Caldwell CH, Sellers RM, Jackson JS. The prevalence of perceived discrimination among African American and Caribbean black youth. Dev Psychol. 2008;44(5):1288-1297. https://doi.org/10.1037/a0012747

17. Trent M, Dooley DG, Dougé J. American Academy of Pediatrics, Section on Adolescent Health, AAP Council on Community Pediatrics, AAP Committee on Adolescence. The impact of racism on child and adolescent health. Pediatrics. 2019;144(2):e20191765. https://doi.org/10.1542/peds.2019-1765

18. Marrast L, Himmelstein DU, Woolhandler, S. Racial and ethnic disparities in mental health care for children and young adults: a national study. Int J Health Serv. 2016;46(4):810-24. https://doi.org/10.1177/0020731416662736 